University of Nebraska - Lincoln

DigitalCommons@University of Nebraska - Lincoln

$10-2013$

\title{
The DSM-5 changes and ADHD: More than a tweak of terms
}

\author{
Brenton Prosser \\ University of Canberra, Australia, Brenton.Prosser@canberra.edu.au \\ Robert C. Reid \\ University of Nebraska-Lincoln, rreid2@unl.edu
}

Follow this and additional works at: https://digitalcommons.unl.edu/specedfacpub

Prosser, Brenton and Reid, Robert C., "The DSM-5 changes and ADHD: More than a tweak of terms" (2013). Special Education and Communication Disorders Faculty Publications. 92.

https://digitalcommons.unl.edu/specedfacpub/92

This Article is brought to you for free and open access by the Department of Special Education and Communication Disorders at DigitalCommons@University of Nebraska - Lincoln. It has been accepted for inclusion in Special Education and Communication Disorders Faculty Publications by an authorized administrator of DigitalCommons@University of Nebraska - Lincoln. 
Published in Australian and New Zealand Journal of Psychiatry (online before print October 24, 20I3), doi: I0.1 I77/00048674I 3509695

Published by Sage Publications on behalf of The Royal Australian and New Zealand College of Psychiatrists. Used by permission.

\title{
The DSM-5 changes and ADHD: More than a tweak of terms
}

\author{
Brenton Prosser \\ Centre for Research and Action in Public Health, University of Canberra, Bruce,Australia; email Brenton.Prosser@canberra.edu.au \\ Robert Reid \\ Faculty of Special Education and Communication Disorders, University of Nebraska-Lincoln, Lincoln, Nebraska USA
}

\begin{abstract}
A recent commentary reignited discussion within this journal about the access by clinicians to the updated Australian National Guidelines on Attention Deficit Hyperactivity Disorder (ADHD) (The Royal Australian College of Physicians, 2009). We seek to extend this debate by noting that the new Diagnostic and Statistical Manual of Mental Disorders (DSM-5) included a number of changes to the definition of ADHD. Given the reliance of these draft national guidelines on the DSM-IV, it can be expected that the DSM-5 changes will also have significant impact on the future form of guidelines, research and clinical practice (Al-Yagon et al., 20l3). Further, the high prevalence of ADHD makes it important for clinicians to understand these recent changes and their implications for diagnosis and treatment (Bell, 20I I).
\end{abstract}

There are five major changes in the new DSM-5. First, a number of examples have been included to elaborate the types of behavior that people with ADHD may exhibit across the lifespan. Second, the age before which symptoms must be manifested has been increased from 7 to 12 years. Third, the number of symptoms required for those over 17 years has been reduced from six to five. Fourth, the previous exclusion criterion for ADHD and autism has been removed. Finally, greater emphasis has been placed on the identification of symptoms across several settings. While the purpose of these changes is to more accurately incorporate the experience of adults affected by ADHD, possible knock-on effects to pediatrics have been suggested (Sibley et al., 20I3).

Estimated prevalence of ADHD in Australia is between 5 and 10\% (The Royal Australian College of Physicians, 2009). Historically, changes to the DSM criteria have resulted in increases in ADHD diagnosis, at times as much as $15 \%$ (Bastra and Frances, 20I2). The DSM-5 changes have the potential for similar increases in ADHD prevalence and concomitant psychostimulant treatment (Coghill and Seth, 20II; Sibley et al., 20I3). However, it is pertinent to examine evidence-based critiques of the DSM-5 changes and their implications for clinical practice.

The main critique of the above changes is that they have not been fully clinically tested (Coghill and Seth, 20I I; Hebebrand and Buitelaar, 20II; Sibley et al., 20l3). Questions have also been raised about the blurring of subtypes and the potential for confusion with comorbid conditions (Bastra and Frances, 2012). For some, this is a positive move that enables diagnostic practices to cater for individual diversity (Bell, 20II), while for others, it leaves the potential for greater misdiagnosis (Bastra and Frances, 20I2).

The increase of age onset from 7 to 12 years has also been subject to critique. Although it is acknowledged that there is no empirical evidence to support either age (Coghill and Seth, $20 \mathrm{II}$ ), the lower age has been preferred in the past because it removes puberty and transition into secondary schooling as confounding variables that may influence behavior (Bastra and Frances, 2012). The shift to the older age is intended to allow more accurate diagnosis of adolescents and adults (Bell, 20I I). However, lifting the age of onset, combined with the requirement to show only symptoms in the past (rather than impairment), may increase levels of diagnosis (Sibley et al., 20I3).

A less controversial change is the greater emphasis on identifying difficulties across multiple settings and the need to rely on reports from third parties in each of these contexts. Those familiar with the DSMIV might observe that this is little change from the previous requirements. And while Coghill and Seth (20II) argue that assessing across settings is commonplace in the UK, Epstein and colleagues (2009) have found that in North America less than $50 \%$ of diagnosticians go beyond parental reports of a child's behavior. There is a lack of empirical evidence on this trend in Australia.

What the above changes have in common is the likelihood of increased diagnosis and psychostimulant treatment (Hebebrand and Buitelaar, 
20II). This would result in a growing demand on clinical services, which would result in increased health costs through the MBS and PBS, and possibly in private costs for families. In the context of existing medical workforce shortages, already tight time demands and limited GP training on ADHD, two outcomes are possible: (i) less rigorously examined assessments by GPs, and/or (ii) increased referrals to psychiatric specialists.

In Australia, only authorized medical practitioners can diagnose ADHD and prescribe psychostimulants. Best practice guidelines recommend that GPs refer to psychiatrists and pediatricians for diagnosis and prescription (The Royal Australian College of Physicians, 2009). In some states and territories, high levels of demand have resulted in GPs and psychologists being authorized as delegates to initiate or continue treatment. In others, the concentration of ADHD diagnosis in the hands of a few specialists has also been noted (Paterson, 2013). Both situations can contribute even further to a significant difference in prescribing practices between medical practitioners (Mitchell et al., 20I2).

Within the USA, uniformity in diagnostic and prescription practices is supported by the American Academy of Child and Adolescent Psychiatry. In Australia, the Royal Australian and New Zealand College of Psychiatrists has produced routine prescribing criteria for ADHD, which some states (e.g. NSW) use to allow members to prescribe without seeking individual approval for each child. However, such arrangements are not widespread and the number of child and adolescent psychiatrists in Australia is in the low hundreds. This means that many children are treated by private pediatricians, which provides the potential for idiosyncratic and expensive practice outside the public system.

Increased referrals will result in greater demand in relation to number of diagnostic assessments, consultation time and administrative tasks.
With these new referrals will also come new responsibilities. There will be more onus on diagnosticians to test for other disorders prior to assessing for ADHD, and changes to onset age will require greater attention to the temporal evolution of behaviors (Sibley et al., 20I3). Thus, the clinical implications of the new DSM-5 conditions may not only be more presentations, but also more complex and time-consuming assessment.

The changes in DSM-5 criteria will also have implications for physicians' interactions with the education system. An emphasis on including teacher reports will present a number of practical difficulties. First, do teachers have the capacity to produce reports that are useful to clinicians? Second, which teachers should report? In the primary school context (where a teacher spends hundreds of hours each year with the same student) this is less problematic. However, later onset age suggests that there will be increased numbers assessed in the secondary school setting (where any given teacher may see over 150 students each week for less than one hour a day). Third, how will clear and efficient lines of communication be established?

There are also more general implications. Better communication will be required between the health professions to facilitate assessment and provide support across multiple settings. Better understandings of which medical practitioners are assessing who and where will be needed to target training on best practice. And, if levels of diagnosis increase, more public resources will be needed to expand multi-modal treatment, so that clinicians are not left prescribing medication as the only available support.

Close analysis shows that the changes in the DSM-5 are more than just a tweak in terminology. The result is likely to be a growth in levels of diagnosis and increased demands on clinical, health and education professionals.

\section{References}

Al-Yagon M, Cavendish W, Cornoldi C, et al. (2013) The proposed changes for DSM-5 for SLD and ADHD: international perspectives - Australia, Germany, Greece, India, Israel, Italy, Spain, Taiwan, United Kingdom, and United States. Journal of Learning Disabilities 46: 58-72.

Bastra $L$ and Frances MD (20I2) DSM-5 further inflates attention deficit hyperactivity disorder. The Journal of Nervous and Mental Disease 200: 486-488.

Bell AS (20II) A critical review of ADHD diagnostic criteria: what to address in the DSM-V. Journal of Attention Disorders I5: 3-10.

Coghill D and Seth S (20II) Do the diagnostic criteria for ADHD need to change? Comments on the preliminary proposals of the DSM-5 ADHD and Disruptive Behavior Disorders Committee. European Journal of Child and Adolescent Psychiatry 20: 75-8I.

Epstein JN, Langberg JM, Lichtenstein PK, et al. (2009) Community-wide intervention to improve the attention-deficit/hyperactivity disorder assessment and treatment practices of community physicians. Pediatrics 122: 19-27.

Hebebrand J and Buitelaar JK (20II) On the way to DSM-V. European Journal of Child and Adolescent Psychiatry 20: 57-60.

Mitchell PB, Levy F, Hadzi-Pavlovic D, et al. (20I2) Practitioner characteristics and the treatment of children and adolescents with attention deficit hyperactivity disorder. Journal of Paediatrics and Child Health 48: 483-489.

Paterson R (20I3) ADHD in Western Australia: an iatrogenic 'epidemic' cured by bureaucracy? Time to focus on the facts. Australian and New Zealand Journal of Psychiatry 47: 88-92.

The Royal Australian College of Physicians (2009) Australian Guidelines on Attention Deficit Hyperactivity Disorder (ADHD) (draft). Canberra: NH\&MRC.

Sibley MH, Waxmonsky JG, Robb JA, et al. (2013) Implications of changes for the field: DHD. Journal of Learning Disabilities 46: 34-42. 